\title{
TERENSKI INDIKATORJI KOT RAZISKOVALNA METODA V SOCIALNI IN POLITIČNI GEOGRAFIJI
}

\author{
Jernej Zupančič \\ Filozofska fakulteta, Oddelek za geografijo, Aškerčeva 2, SI-I000 Ljubljana \\ e-mail: jernej.zupancic@guest.arnes.si
}

Pregledni znanstveni članek

COBISS 1.02

\section{Izvleček}

Prispevek obravnava vprašanje uporabe nekaterih izbranih metod socialne geografije na delovnih področjih politične geografije. V tem okviru namenja posebno pozornost uporabi različnih terenskih indikatorjev, s katerimi si pomagamo pri pojasnjevanju procesov, pojavov in problemov. Kljub nekaterim slabostim je metoda uporabna tudi sedaj, še posebej pri proučevanju manjšinskega vprašanja in kriznih območij.

Ključne besede: socialna geografija, politična geografija, Slovenija, raziskovalne metode

\section{THE ROLE AND FUNCTION OF FIELD INDICATORS AS A RESEARCH METHOD IN SOCIAL AND POLITICAL GEOGRAPHY}

\begin{abstract}
The paper analyses the methods of field research work, used in social geography, as well as the opportunity for use those methods in political geography. Concerning to strong connection between social and political geography in Slovenia, they have some common research topics, particulary in research of minority patterns and crisis areas. Despite some weaknesses, the method of field indicators is usable in political geography, too.
\end{abstract}

Key words: social geography, political geography, Slovenia, research methods 


\section{UVOD}

\section{I.I Kako videti procese $\mathbf{v}$ pokrajini?}

Nagel razvoj socialne geografije v obdobju po drugi svetovni vojni je v veliki meri temeljil na obsežnem in podrobnem terenskem delu ter izrabi statističnih podatkov. Poleg kvantitativne analize so imeli pomembno mesto $\mathrm{v}$ metodološkem instrumentariju tudi t.i. terenski indikatorji: vidni elementi v pokrajini, na podlagi katerih je bilo mogoče sklepati in dokazovati pojave, proces in probleme v pokrajini. Ta metoda je bila daleč od nekdanjega deskriptivnega zaznavanja; bila je poglobljena analiza, ki je podatke uradne statistike potrjevala, dopolnjevala, jih nadomeščala ali jim nasprotovala.

Namen prispevka je osvetliti nekatere priložnosti uporabe predvsem terenskih metod in tehnik pri proučevanju nekaterih sodobnih političnogeografskih raziskovalnih problemov. Med tem posebej izpostavljamo metodo terenskih indikatorjev. Zaradi omejenega prostora se bomo osredotočili le na nekatere izbrane primere.

\section{OD SOCIALNE K POLITIČNI GEOGRAFIJI}

Socialna geografija se je v Sloveniji uveljavila postopoma in tako rekoč neopazno. Za njen razvoj in uveljavljanje je zaslužen predvsem Vladimir Klemenčič, ki je ob svojem raziskovalnem delu zlasti podeželskih in perifernih območij ter v tesnem sodelovanju zlasti s t.i. »Münchensko« socialnogeografsko šolo K. Rupperta in še nekaterih vidnih nemških socialnih geografov izpostavil »problem« kot eno izmed ključnih vodil. Prav »problemska« naravnanost je tista, po katerem letošnjega jubilanta (80. let življenja) poznajo ne le številne generacije geografov, temveč tudi vrsta predstavnikov drugih ved in strok, s katerimi se je socialnogeografski pristop tematsko pričel soočati, se prekrivati in sodelovati. Problemski pristop je torej vodil $\mathrm{v}$ interdisciplinarnost. Vendar ob tem geografija ni izgubljala svoje prostorske substance; nasprotno, prav zaradi nje se je uveljavila kot povsem enakovredna veda na področjih kot so npr. regionalni razvoj in narodno vprašanje. Uvajanje socialne geografije je $\mathrm{v}$ šestdesetih in sedemdesetih letih sprožalo precej burne polemike znotraj geografske stroke (Ilešič, 1979, 259-279), ki se je tedaj pri nas in v svetu soočala s krizo svoje geografske identitete: ena (enotna, skupna in kompleksna) geografija ali več geografij (geografska specializacija). Dilema med enotnostjo in specializacijo se je močno odražala zlasti na področju metod geografskega dela. Rastoči obseg podatkov je nudil čedalje boljše možnosti različnih kvantitativnih pristopov in prav geografija je $\mathrm{v}$ povezanosti $\mathrm{z}$ razvojem tematske kartografije odpirala nova polja raziskovanja in demonstracije procesov, ki so hitro spreminjali pokrajinsko podobo in njen vsakokratni družbeni pomen. Vendar je terensko delo z različnimi tehnikami ostalo eno izmed temeljev geografskega dela in poznavanja pokrajine. Med temi posebej izpostavljamo metodo terenskih indikatorjev: staro, klasično, a pogosto še dovolj učinkovito in torej še vedno uporabno za osvetlitev pojavov in procesov tedaj, ko različni kvantitativni (predvsem statistični) podatki niso dosegljivi ali pa jim ne moremo zaupati. 
Podobno neopazno kot je uvajal socialno geografijo ima Klemenčič zasluge tudi za razvoj politične geografije. Tako se je predvsem z delom na področju narodnega vprašanja, točneje narodnih manjšin, poglobil v klasične političnogeografske teme. Ko je k temu dodal še probleme meje in obmejnih območij (Klemenčič, 1987), je bilo imenovanje novega geografskega problemskega področja zgolj vprašanje (kratkega) časa. Za razvoj slovenske politične geografije je bil postopen prehod iz socialne v politično geografijo predvsem stvar izbire proučevanega predmeta. Toda buren razvoj politične geografije je ob globalnih geopolitičnih premikih v Evropi in tudi v svetu postavil tudi slovenski politični geografiji vprašanje raziskovalnih metod in tehnik. To vprašanje je tembolj pomembno tudi zato, ker se danes nahajamo ob preobilici različnih dostopnih informacij, s pomočjo katerih je mogoče opredeliti in analizirati sodobne pojave, procese in probleme v pokrajini. Postavljamo si vprašanje, ali in v kolikšni meri so nekatere metode in tehnike raziskovalnega dela v socialni geografiji uporabne tudi v sodobni politični geografiji.

\section{UPORABNOST INDIKATORJEV $V$ KONCEPTIH SOCIALNOGEOGRAFSKEGA PROUČEVANJA}

Socialna geografija se je razvila iz antropogeografije in pod močnim vplivom socioloških znanosti. Poleg filozofskih tokov, predvsem posibilizma francoske šole, ki so pričeli postopoma izrinjati še pred stoletjem močno zasidrane deterministične poglede, so razvoju socialnogeografske koncepcije v znatni meri botrovale tudi družbenogospodarske razmere $\mathrm{v}$ Srednji in Zahodni Evropi po drugi svetovni vojni. Po stabilizaciji političnih razmer in uveljavitvi blokovske polarizacije in hladne vojne, je v šestdesetih letih 20. stoletja večina kapitalistične Evrope pričela razvijati model socialne države in družbe blagostanja. Še vedno prevladujoči koncept industrijskega razvoja se je ob naglem uveljavljanju storitvenih dejavnosti moral postopoma umikati nastopajoči urbani terciarizirani družbi. Krepitev srednjega sloja in odločna prevlada urbanega načina življenja sta korenito posegli v način prostorskega vedenja prebivalstva. V teh okoliščinah je socialna geografija ponudila koncept raziskovanja, ki je kot temeljno podmeno postavil prostorsko organizacijo ljudi, njihovo obnašanje, potrebe in prostorski doseg. Izhodiščna hipoteza je bila, da smemo s precejšnjo verjetnostjo pričakovati, da bodo imeli pripadniki iste socialne skupine podoben stil (način) življenja in torej tudi potrebe (Ruppert, Schaffer, Maier, Paesler, 1977, 27). Nesporno je v tej koncepciji mogoče opaziti precejšen vpliv sociologije, ki so v nekaterih okoljih (zlasti nizozemskih in ameriških) - zdi se - celo dobili prevladujoč vpliv. Bistven prispevek k razumevanju socialne in prostorske dinamike so pozneje dodali ameriški avtorji, povzemajoč pri tem tudi predpostavke »vedenjske« / behavioristične teorije (Guld, 1980). Behaviorizem je relativiziral trdnost socialne skupine s predpostavko, da so individualna odstopanja, na katera lahko vplivajo zelo različni dejavniki, lahko zelo velika ali sploh prevladujoča.

V Sloveniji so bile razmere precej drugačne. Za razliko od srednje- in zahodnoevropskih držav je bil socialni prehod iz agrarne $\mathrm{v}$ industrijsko in potem $\mathrm{v}$ postindustrijsko (terciarno) družbo bistveno hitrejši. Klemenčič dokazuje, da se je zgodil praktično v eni sami generaciji (Klemenčič, 2003, 41). Poleg tega moramo upoštevati tudi vrsto posebnosti, ki izhajajo iz 
lastnosti socialističnega družbenega ustroja na eni ter geopolitičnega položaja Slovenije. Vsekakor je bil družbeni in prostorski razvoj Slovenije sprva pod močnim vplivom industrializacije; ta je oblikovala široke cone dnevnih migracij in s tem povzročila opazne regionalne razlike (Klemenčič, 1971, 198-200). Kasneje so se te še povečevale, vse do danes (Klemenčič, 2002). V luči uporabljenih raziskovalnih metod, pristopov in tehnik je prav tematika podeželja zelo primerna za osvetlitev nekaterih posebnosti socialnogeografskega koncepta. Poleg kartiranja kot najbolj značilne geografske metode bi si tedaj in tudi še danes težko predstavljali resno raziskavo, ki bi v svojem metodološkem instrumentariju ne zajemala tudi anketiranja. Kljub precej podrobnim in na splošno dosegljivim statističnim podatkom je bilo skoraj nemogoče kompleksno proučiti lokalne razmere in iskati probleme in perspektive brez omenjene najpogostejše oblike (tudi geografskega) terenskega dela. Statistični podatki so pri nagli družbeni dinamiki hitro zastareli in so po nekaj letih predstavljali le še okvirno informativno vrednost. Prav Klemenčičeve študije razvoja perifernih območij in še posebej razmer na narodno mešanih območjih so poudarile vrednost terenskih metod zbiranja informacij. Oster kritik avstrijskih popisov prebivalstva po občevalnem jeziku je vztrajno dokazoval njihovo manipulativno naravo $\mathrm{v}$ vseh fazah: priprave in izvedbe popisa ter objave rezultatov (Klemenčič, 1960; Klemenčič, 1990). V omenjeni razpravi omenja avtor vrsto posrednih »dokazov«, da uradna statistika »laže«. Drobni, na videz nepomembni indikatorji so torej bistveno pripomogli k rušenju statistično dokazovanega mita o izginotju manjšinske skupnosti. Popisnim podatkom ni bilo mogoče zaupati, zato so zlasti»etnične« statistike mnogi avtorji jemali z veliko mero previdnosti. Interpretacija rezultatov je zahtevala vrsto dodatnih pojasnil. Obširnih anketiranj, ki bi lahko do neke mere nadomestile (skoraj) neuporabne podatke uradnih popisov po narodni, verski ali jezikovni pripadnosti, ni bilo mogoče izvajati zaradi časovnih, finančnih ali pravnih razlogov. V podobnih primerih se je bilo treba zanesti zlasti na daljša usmerjena in kontinuirana opazovanja ter si pri tem pomagati predvsem z različnimi terenskimi indikatorji. Prav omenjeno metodo je Klemenčič s pridom uporabil pri dokazovanju svojih tez o nereprezentativnosti statističnih popisov. Metodo terenskih indikatorjev so svetovali za dokazovanje in / ali ilustracijo procesov tudi avtorji že omenjene socialne geografije (Ruppert, Schaffer, Maier, Paesler, 1977, 76-78). Gre predvsem za vrsto pojavov, ki so v pokrajini vidni in prepoznavni in so rezultat določenega prostorskega ravnanja pripadnikov določenih socialni skupin (na primer izgled stanovanjske hiše in njene okolice, posredno torej izgled naselij). Nič manj pomembna ni uporaba teh »ambientov« danes, še posebej na področju aplikativne, v planiranje usmerjene socialne geografije. Ali si je mogoče zamisliti, da je osebno prizadevanje posameznika pri olepševanju svojega bivalnega okolja nevredno znanstvenih spoznanj? Saj nam vendar ravno oblikovana kulturna pokrajina pove največ o vzdrževalcu le-te! Sodobna socialna geografija se od tega ne umika; izziv kvantifikacije vidnega $\mathrm{v}$ pokrajini pa je vendarle ostal (Werlen, 2000). Metodo je mogoče uporabljati tudi na drugih področjih geografske stroke, vendar je nekako ostala prepoznavni znak predvsem socialne geografije. Njena učinkovitost je precej odvisna od izkušenosti opazovalca. Kljub preprostosti in pogosto očitani površnosti je metoda uporabe terenskih indikatorjev potrdila svojo veljavo in se ohranila vse do danes. Celo več! Zdi se, da ob (ponovnem) uveljavljanju kvalitativne analize tudi metoda uporabe terenskih indikatorjev celo pridobiva na pomenu, še posebej na področjih, kjer je zaradi različnih razlogov rezultatov statističnih popisov in 
evidenc ni na razpolago ali pa upravičeno dvomimo v njihovo kakovost. To pa so pogosto področja, ki jih sicer obravnava politična geografija.

\section{POTREBE PO TERENSKIH RAZISKOVALNIH METODAH V POLITIČNI GEOGRAFIII}

Zgoraj prikazane terenskemetode proučevanja imajo s politično geografijo vrsto sorodnih, če ne kar skupnih potez. Še posebej velja to za raziskovanje manjšinskega vprašanja in meje. Čeprav Klemenčič tedaj ni imenoval svojih študij o koroških Slovencihniti političnogeografske, niti (zlasti sprva) socialnogeografske, sodijo po svoji metodološki naravnanosti v koncept socialnogeografskega dela, po tematiki pa predvsem v okvir politične geografije. A tudi sicer imata socialna in politična geografija več stičišč, kot se to navadno priznava. Obe namreč v bistvu izhajata iz antropogeografije. Toda medtem ko je socialna geografija odgovarjala na izzive politično razmeroma mirnega obdobja blokovske razdelitve in ideološke polarizacije Evrope in sveta, ima politična geografija nekoliko daljšo in predvsem pestrejšo zgodovino. $\mathrm{Na}$ njen razvoj sta $\mathrm{v}$ začetni fazi odločilno vplivala geografski determinizem in socialni darvinizem kot pomembni idejni struji druge polovice 19. stoletja. Odločilnega pomena za razvoj nemške politične geografije F. Ratzla in le malo pozneje tudi angleške šole politične geografije MacKinderja so bile tudi družbene in politične okoliščine. Le-te so narekovale, da je že zelo zgodaj politična geografija postala »geopolitika«, ki je svoje akademsko poslanstvo razumela kot priložnost za novo razdelitev sveta, pretežno po meri lastne države (Parker, 1997). Poznejši razvoj te geografske discipline je kljub preziru, ki ga je bila deležna zaradi očitnega "političnega« angažiranja, vodil k njeni uveljavitvi. Temeljni predmet političnogeografskega proučevanja je država, njena organizacija, potrebe in razvojne možnosti, pa tudi vse tiste organizirane skupine prebivalstva, ki imajo namen in možnosti obvladati določen teritorij. Tako socialno kot politično geografijo zanimajo torej skupine prebivalstva in njihovi prostorski učinki. Toda medtem ko pri socialni geografiji zadoščajo kriteriji določene homogenosti, po katerih je člane te skupine prepoznati, se politična geografija posveča izključno organiziranim oblikam povezovanja ljudi; te torej morajo biti realna organizirana skupnost. Vendar je zmotno misliti, da političnogeografske študije ne premorejo zelo podrobnih terenskih raziskovanj. Postavimo za primer območje dvojezične Koroške v petdesetih letih, takoj po drugi svetovni vojni. Klemenčič je tedaj pričel s podrobnimi analizami prebivalstva, s posebnim ozirom na jezikovno (dejansko narodno) sestavo prebivalstva (Klemenčič, 1952). Vendar avtor tedaj ni imenoval svojih prispevkov niti za socialno- niti za političnogeografske. Le malo pozneje je izšlo delo ameriškega avtorja Randalla z naslovom »Politična geografija Celovškega plebiscitnega območja« (Randall, 1955), ki je pozorno sledilo zlasti socialnim, demografskim in kulturnim vidikom diferenciacije koroškega prebivalstva ter spremljajočim pojavom in procesom, kot je npr. vprašanje razmejitve. Oba avtorja sta torej v istem času delala na isti temi na podoben način!

Zlasti proučevanje manjšin sodi med zelo kompleksna opravila znotraj politične geografije, ki ima tudi nekaj posebnosti glede uporabe metod in tehnik, ki so sicer dobro znane tudi v konceptu socialne geografije. Poglavitni vir podatkov - popisi prebivalstva so pogosto zavajajoči, zato 
so že ocene števila pripadnikov neke manjšinske skupnosti praviloma narejene na podlagi uporabe različnih terenskih indikatorjev. Še posebej opredeljevanje njihovega dejanskega položaja zahteva dobro poznavanje lokalnih razmer. Različni kvantitativni podatki (npr. podatki popisov) so lahko v veliko pomoč; vendar ne smemo prezreti vseh ostalih informacij, ki jih je mogoče zbrati razmeroma preprosto, čeprav zamudno. Med odlične tovrstne indikatorje sodijo na primer napisi na javnih in zasebnih zgradbah, sakralnih spomenikih, na pokopališčih, na izobraževalnih in drugih ustanovah, v različnih medijih in podobno. Težko si zgolj na podlagi statističnih podatkov ustvarimo podobo o zapleteni problematiki romskih naselij. Terenski indikatorji so tedaj v veliko pomoč kot dodatni, posredni »dokazi«. Proučevanje manjšinskih in izseljenskih situacij torej zahteva daljše opazovanje in večkratno preverjanje. Sistematično vzorčenje bi se lahko hitro sprevrglo v zavrnitev potencialnih sogovornikov, s tem pa tudi zaprla pot nadaljnjega spoznavanja okoliščin in procesov $\mathrm{v}$ poselitvenem, simbolnem in funkcionalnem prostoru. Poleg tega so zlasti manjše in prostorsko razpršene skupnosti dostikrat statistično in tudi dejansko nevidne. Odkrijemo jih lahko le z dostopanjem od člana do člana, pri čemer je sprotno ustvarjanje zaupanja in poznavanja ključnega pomena. Šele potem lahko sledijo tudi ankete in poizkusi kvantifikacije pojavov, a z mnogimi omejitvami.

Nekoliko drugače je na področju proučevanja kriznih območij, ki imajo v sodobni politični geografiji prav tako zelo vidno mesto. Tudi tam zaradi pogosto kaotičnih razmer uradnih statistik ni ali pa jim ni mogoče zaupati. Raziskovanje se mora torej nasloniti (poleg različnih ocen) prav na ugotovljive terenske indikatorje, kot so na primer vidne poškodbe, opuščena naselja, begunci, gospodarstvo, ki je namenjeno izključno trenutnemu preživetju, odsotnost planiranja, očitna (tudi prostorska) anarhija in podobni pojavi (Zupančič, 2005, 5). Toda zgolj opis sam po sebi ni dovolj. Ugotovljena pokrajinska slika, ki jo dobimo na podlagi enega ali več indikatorjev, zahteva odgovore na vprašanja: kdaj, zakaj, koliko, koliko časa? Tudi znamenja globalizacije lahko uporabimo kot »dokazno gradivo« k oblikovanju slike o današnji prostorski in družbeni stvarnosti. Proučevanje vidnih elementov v pokrajini torej ni zastarela deskripcija, temveč del poglobljenega študija po načelih kvalitativne analize.

\section{ZAKLJUČEK}

Slovenska politična geografija jasno dokazuje svoje korenine v razvoju socialne geografije. Ta je s podrobnimi empiričnimi raziskavami obmejnih in narodno mešanih območij posegla v klasično političnogeografsko delovišče. Metoda uporabe terenskih indikatorjev, ki so je v socialnogeografskih študijah pogosto uporabljali, izkazala kot povsem primerna tudi na področjih politične geografije. Vendar se tu odpira vrsta vprašanj predvsem glede bolj sistematičnega pristopa pri uporabi terenskih indikatorjev. Pridobljene izkušnje nagibajo prav v to smer. Po drugi strani pa se je treba ozreti tudi na nove razsežnosti slovenske politične geografije, ki je od lokalnosti (periferna, obmejna in narodno mešana območja) pričela odpirati bistveno širša vprašanja sodobnih geopolitičnih razmerij in procesov predvsem v združeni Evropi. Za dokazljivost globalnih procesov in tokov pa potrebujemo tudi nove indikatorje. Če se je v devetdesetih letih ta hitro razvijajoča geografska panoga še lahko naslanjala na izsledke podrobnih socialnogeografskih študij in uporabljala praktično enake pristope, metode 
in tehnike, vključno z uporabo terenskih indikatorjev, postaja danes jasno, da si bo morala sodobna politična geografija, soočena z novimi izzivi postindustrijske informacijske družbe in globalnih gospodarskih, političnih in kulturnih tokov, iskati tudi nove, dovolj prepoznavne terenske indikatorje, jih sistematično urejati in vrednotiti. Metoda torej ostaja izziv tudi na delovišču sodobne politične geografije.

\section{Literatura}

Guld, J.R., 1980, An Introduction to Behavioural Geography. Oxford University Press, Oxford Ilešič, S., 1979, Pogledi na geografijo. Ljubljana

Klemenčič, V., 1952, Rast prebivalstva na slovenskem Koroškem v obdobju 1934-1951, Geografski vestnik, letnik 24, Ljubljana, str. 115-134

Klemenčič, V., 1959, Pokrajina med Snežnikom in Slavnikom. SAZU, Ljubljana

Klemenčič, V., 1960, Kritični pretres avstrijskega popisa 1951 z ozirom na jezikovno strukturo na Koroškem, Razprave in gradivo, št. 2, Ljubljana, str. 101-182

Klemenčič, V., 1971, Prostorska diferenciacija Slovenije po selitveni mobilnosti prebivalstva, Geografski zbornik, št. 12, Ljubljana, str. 135-220

Klemenčič, V., 1987, Državna meja na območju SR Slovenije in obmejna območja kot geografski fenomen, Razprave in gradivo, št. 20, Ljubljana, str. 57-81

Klemenčič, V., 1990, Metodologija uradnih popisov prebivalstva pripadnikov slovenske manjšine v Italiji, Avstriji in na Madžarskem, Narodne manjšine, zbornik, Ljubljana, str. 31-45

Klemenčič, V., 2002, Procesi deagrarizacije in urbanizacije slovenskega podeželja, Dela, št. 17, Ljubljana, str. 7-21

Klemenčič, V., 2003, Neue Impulse zur sozialgeographischen Umstrukturierung nach Verselberständigung Sloweniens 1991, Dela 19, Ljubljana, str. 39-47

Parker, G., 1997, Geopolitika v 20. stoletju, Ljubljana (Uvod Iztok Simonitti)

Randall, R.R., 1955, The Political Geography of The Klagenfurt Plebiscite Area, Faculty of Clark University, Worcester

Ruppert K., Schaffer F., Maier J., Paesler R., 1977, Sozialgeographie. Georg Westermann Verlag, Braunschweig

Werlen, B., Sozialgeographie, Stutgart

Zupančič, J., 1999, Slovenci v Avstriji. Ljubljana

Zupančič, J., 2005, Geografski vidik kriznih območij, Geografski obzornik, letnik 52, št. 3, Ljubljana, str. 4-10 


\section{THE ROLE AND FUNCTION OF FIELD INDICATORS AS A RESEARCH METHOD IN SOCIAL AND POLITICAL GEOGRAPHY}

\section{Summary}

Slovene social geography was developed in 1960-ies and 1970-ies, thanks to Vladimir Klemenčič, who was beginner and one of most important author of this part of geographical sciences until today. Strong connections with many research centres in the Europe, particularly with s.c. »german« socialgeographical school as well as many field research works on rural landscape, peripheral areas and ethnic mixed territories brought new experiences. In very detailed analysis, devoted to contemporary open spatial and social problems, Klemenčič's research style came to the voice. To problems oriented social geography promoted him and his work. Among the generations of geographers and non-geographers he was known as "problem- and process- geographer«. In order to follow all this dynamism of spatial and social transformation, the observation of cultural landscape brought many informations about the structure and processes each time. The field indicators seemed at that time, some decades ago, alredy forgotten method. But in the concept of social geography, this method was used quite often. It was used as some kind of confirmation-method for veryfiing of statistical data and, by other hand, for substitution of official statistics. The use of field-indicators opened new aspects in scientific methodology, particulary after »return « of qualitative analysis. In slovenian context, political geography starts to develope not by way of thinking and from specific geopolitical acpects, but by topic. Since early 1950-ies, the studies of ethnic problems of Carinthian Slovenes (Austria) based not only on critical observation and quantitative analysis of austrian ethnic (linguistic) statistics, but by using several field-indicators. There were polemic discussions about the validity of both methods: statistical (official) or formal and those based on indicators. Despite some weaknesses, practically all estimations of number of minority population were made considering this unpunctual and old-fashioned method. In a modern political geography, extended between global and local view on the world, the method of field indicators still represent a challenge. The »visible« in the landscape remained his validity undoubtly. The only question is how to $»$ read $«$ traces of spatial and social processes and how to recognize the problems systematically. 